\title{
PLANO DIRETOR INTEGRADO DE BOTUCATU: A FAVOR OU CONTRA O DESENVOLVIMENTO SUSTENTÁVEL?
}

\author{
Carolina Gomes de Souza
}

Arquiteta e Urbanista formada pela Faculdade de Arquitetura e Urbanismo Mackenzie. Trabalha atualmente na Secretaria Municipal de Desenvolvimento Urbano da Prefeitura Municipal de São Paulo. Desenvolveu pesquisas relacionadas ao desenvolvimento sustentável e Paisagem das cidades sustentáveis. Possui Pós-graduação na Holanda em "Urban Management Tools for Climate Change" NA Erasmus University. Aluna especial na disciplina AUP - Projeto Sustentável, do programa de Pósgraduação da Faculdade de Arquitetura e Urbanismo da Universidade de São Paulo.

E-mail: carol_gds@hotmail.com

\begin{abstract}
Resumo
Em uma época em que muito se discute a questão do desenvolvimento sustentável e a construção das cidades sustentáveis, como forma de adaptação e/ou mitigação dos efeitos das "Mudanças Climáticas", de que forma o existente método de desenvolvimento urbano colabora ou dificulta para que tais diretrizes sejam incorporadas? Visto a grande importância da cidade de Botucatu, desde sua localização, até a concentração de recursos naturais, APA (Área de Preservação Ambiental) de Botucatu, recarga do Aqüífero Guarani, entre outros, a cidade necessita que suas diretrizes de desenvolvimento caminhem na direção do sustentável e, portanto, que estejam incorporadas em suas leis e planos. Esta pesquisa visa analisar os principais conceitos de desenvolvimento sustentável e cidades sustentáveis e identificá-los ou não, nas premissas de desenvolvimento urbano, do Plano Diretor Integrado de Botucatu.
\end{abstract}

Palavras-chave: Desenvolvimento urbano sustentável, cidades sustentáveis, Mudanças Climáticas, Plano Diretor Integrado de Botucatu, APA Botucatu. 


\title{
BOTUCATU INTEGRATED MASTER PLAN: FOR OR AGAINST SUSTAINABLE DEVELOPMENT?
}

\begin{abstract}
In a time when occurs much discussion about sustainable development and construction of sustainable cities, as adaptation and / or mitigation actions against the effects of "Climate Change", how the existing method of urban development contributes or not to such guidelines? Since the great importance of Botucatu City, from its location to the concentration of natural resources, APA (Environmental Protected Area) in Botucatu, the Guarani Aquifer recharge, among others, the city needs to develop its guidelines in the direction of sustainability, and therefore incorporate them into its laws and plans. This research aims to review key concepts of sustainable development and sustainable cities and identify them or not, in the premises of urban development, the Integrated Plan of Botucatu.
\end{abstract}

Keywords: Sustainable urban development, sustainable cities, Climate Change, Botucatu Integrated Master Plan, APA Botucatu.

\section{DESENVOLVIMENTO SUSTENTÁVEL}

As discussões, reuniões e conferências decorridas nos últimos 50 anos, a respeito do meio ambiente, das Mudanças Climáticas, da escassez dos recursos naturais e o futuro do planeta Terra, despertaram a atenção da sociedade para mitigar e/ou minimizar os danos ambientais no mundo, atingindo até os campos de arquitetura e do planejamento urbano.

Com a promessa de eventos naturais mais extremos, como por exemplo, chuvas mais rápidas e intensas, secas, aumento de temperatura, e aumento dos efeitos das "ilhas de calor", entre outros, os estudos referentes às conseqüências das Mudanças Climáticas nas cidades sugerem que estas previnam e/ou minimizem tais efeitos incorporando em seu tradicional método de planejamento e desenvolvimento urbano medidas de desenvolvimento sustentável e conseqüentemente promoção das cidades sustentáveis. 
O conceito de "desenvolvimento sustentável", adaptado pela "Agenda 21"1, foi usado pela primeira vez no "Relatório de Brundtland"(que também ficou conhecido como relatório "Nosso Futuro Comum"), em 1987, criado pela Comissão Mundial sobre Meio Ambiente e Desenvolvimento ${ }^{2}$.

"O desenvolvimento que procura satisfazer as necessidades da geração atual, sem comprometer a capacidade das gerações futuras de satisfazerem as suas próprias necessidades, significa possibilitar que as pessoas, agora e no futuro, atinjam um nível satisfatório de desenvolvimento social e econômico e de realização humana e cultural, fazendo, ao mesmo tempo, um uso razoável dos recursos da terra e preservando as espécies e os habitats naturais." (NOSSO FUTURO COMUM: 1991)

O desenvolvimento sustentável propõe que a sociedade deve se desenvolver cultural, econômica e socialmente, e ao mesmo tempo preservar a biodiversidade e os ecossistemas naturais.

"[...] para a sustentabilidade é necessária a adoção de novas práticas sociais que estabeleçam relações de produção e exploração dos recursos garantindo sua manutenção (o equilíbrio dinâmico da natureza), o que depende de uma reelaboração científica dos conhecimentos (ecotecnologia) observando a natureza (e/ou o ambiente) de outra perspectiva, a de otimização das funções ecológicas. Isto implica em adotar uma economia política do ambiente, na qual todos os atores envolvidos (Estado, movimentos sociais, populações,

\footnotetext{
1 A Agenda 21 foi um dos principais resultados da conferência Eco-92, ocorrida no Rio de Janeiro, Brasil, em 1992. É um documento que estabeleceu a importância de cada país a se comprometer a refletir, global e localmente, sobre a forma pela qual governos, empresas, organizações nãogovernamentais e todos os setores da sociedade poderiam cooperar no estudo de soluções para os problemas sócio-ambientais.
}

2 A Comissão Mundial sobre Meio Ambiente e Desenvolvimento foi criada em 1983 pela Assembleia das Nações Unidas. 
cientistas e outros) mobilizam-se por uma gestão ambiental integrada na qual a conservação é prioritária e fundamental" (NUCCI E FÁVERO: 2003 apud FAVERO: 2007)

No campo do planejamento urbano o "desenvolvimento sustentável" repercutiu em estudos e propostas para o desenvolvimento das cidades de formas que estas cresçam embasadas no conceito de "cidades sustentáveis".

\section{AS CIDADES SUSTENTÁVEIS}

Cada vez mais dissociada da natureza, a cidade da sociedade moderna se tornou sofisticada, com inúmeras possibilidades de lazer, cultura e disponibilidade dos mais variados serviços. Assim, as áreas urbanas ficaram "atraentes" e concentram a cada ano mais pessoas e um fluxo intenso de novos moradores provenientes de áreas rurais.

"As cidades são o centro da produção e do consumo da maior parte dos bens industriais e acabaram se transformando em parasitas da paisagem, em enormes organismos drenando o mundo para seu sustento e energia: inexoráveis consumidores e causadores de poluição". (ROGERS: 1997)

O acúmulo de pessoas e o crescimento acelerado das áreas urbanas, juntamente com a falta de planejamento e preparo de algumas, fez com que as cidades sofressem grandes danos ambientais, com os quais o homem convive diariamente. São eles: a poluição do ar, dos rios, do solo; a destruição progressiva dos ecossistemas (desmatamento, queimadas); a escassez de áreas verdes e públicas; as doenças; as mudanças climáticas, como as "ilhas de calor" e o "efeito estufa".

Muitos estudos e propostas foram e vêm sendo realizados, a fim de gerar uma projeção do que seria uma cidade sustentável, que absorvam o enorme aumento no crescimento urbano, respeitando o meio ambiente e não colocando em risco as futuras gerações.

Primeiramente as cidades devem ser entendidas como organismos únicos, ou seja, suas atividades não podem ser separadas ou vistas isoladamente, todas as atividades ocorridas dentro dela a constituem de forma única e integrada. 
Assim, segundo Herbert Girardet, "a solução está na busca de um "metabolismo" circular nas cidades, onde o consumo é reduzido pela implementação de eficiências e onde a reutilização de recursos é maximizada. Devemos reciclar materiais, reduzir o lixo, conservar os recursos não-renováveis e insistir no consumo dos renováveis. Uma vez que grande parte da produção e do consumo ocorre nas cidades, os atuais processos lineares de produção, causadores de poluição, devem ser substituídos por aqueles que objetivem um sistema circular de uso e reutilização".

Outro fator a ser analisado é que a estruturação atual e o zoneamento das cidades em geral, não são eficientes. Estes promovem uma setorização por "zonas" diferentes para cada atividade, ou seja, a moradia, o trabalho e o lazer são dispersos e distantes uns dos outros, o que além de não promoverem o convívio das pessoas, dificultam o deslocamento, que passa a ser quase exclusivamente por automóveis, o que gera alto grau de poluição e congestionamentos, além de dificultarem a prática e o usufruto das horas de lazer.

Uma cidade sustentável deve compor um sistema diversificado, ou seja, com pequenos núcleos que comportem todas as atividades necessárias para o cotidiano ideal de um cidadão, e que os deslocamentos sejam minimizados e percorridos a pé ou de bicicleta. Estes núcleos, por sua vez, devem ser interligados pelo transporte público. Este sistema proporciona um maior convívio entre as pessoas e o convívio do homem com a natureza, além de minimizar os impactos ambientais causados pelo uso dos automóveis, como a poluição, como também minimiza as "ilhas de calor" das cidades, pois pequenos parques urbanos contribuem para refrescar e preservar o micro clima da área.

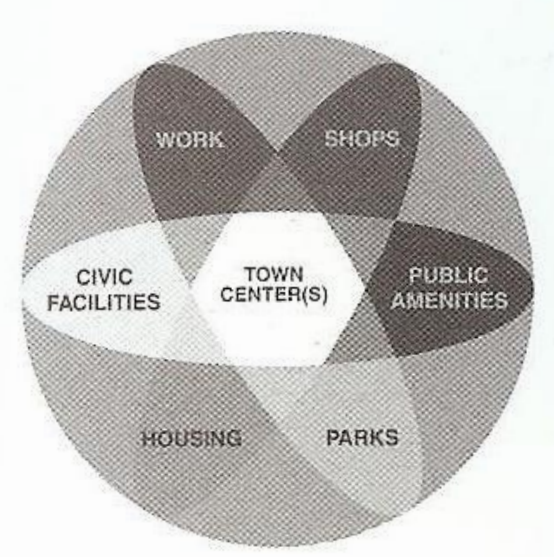

COMPLETE AND INTEGRATED COMMUNITY

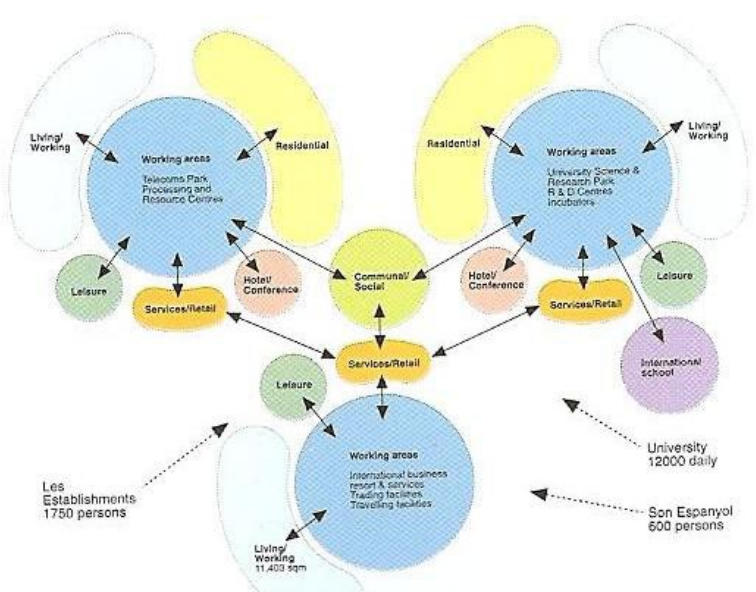

Figura 1: Distribuição de atividades em uma cidade sustentável. Fonte: RUANO: 1999 
Uma cidade sustentável contempla objetivos sociais, políticos, culturais e ambientais. Esta deve promover a distribuição justa dos serviços, a participação da comunidade na tomada de decisões, proposta pela Agenda 21, deslocamentos acessíveis e um ambiente saudável e digno para o homem viver, com áreas públicas de cultura, lazer e verdes.

Segundo Branco, para a cidade atingir um equilíbrio e aperfeiçoar as condições de vida no ambiente urbano, ela deve implantar algumas medidas e iniciativas:

1 "A implementação de parques e rua arborizadas, aumentando o verde e as áreas de infiltração das águas das chuvas."

2 "A implantação de um sistema eficiente de transportes coletivos."

3 "A construção de edifícios mais ecológicos."

4 "A implantação de sistemas mais adequados de saneamento: o tratamento dos esgotos domésticos e industriais." (BRANCO: 1991)

\section{A CIDADE DE BOTUCATU}

Botucatu é um município localizado no interior do Estado de São Paulo, com 130.348 habitantes, população estimada em 2009 (IBGE). As principais vias de acesso da capital à Botucatu são as rodovias Marechal Rondon e Castelo Branco, com uma distância aproximada de 235 km.

Ocupa uma área de 1.482,87 km² e faz limites com os municípios de Anhembi, Bofete, Pardinho, Itatinga, Avaré, Pratânia, São Manuel, Dois Córregos e Santa Maria da Serra.

O município é drenado por duas bacias hidrográficas: do rio Tietê, ao norte, onde está localizado um de seus principais afluentes, a foz do rio Piracicaba; e do rio Pardo, ao sul, sendo um afluente do rio Paranapanema, ele percorre uma extensão de $67 \mathrm{~km}$ no município. 


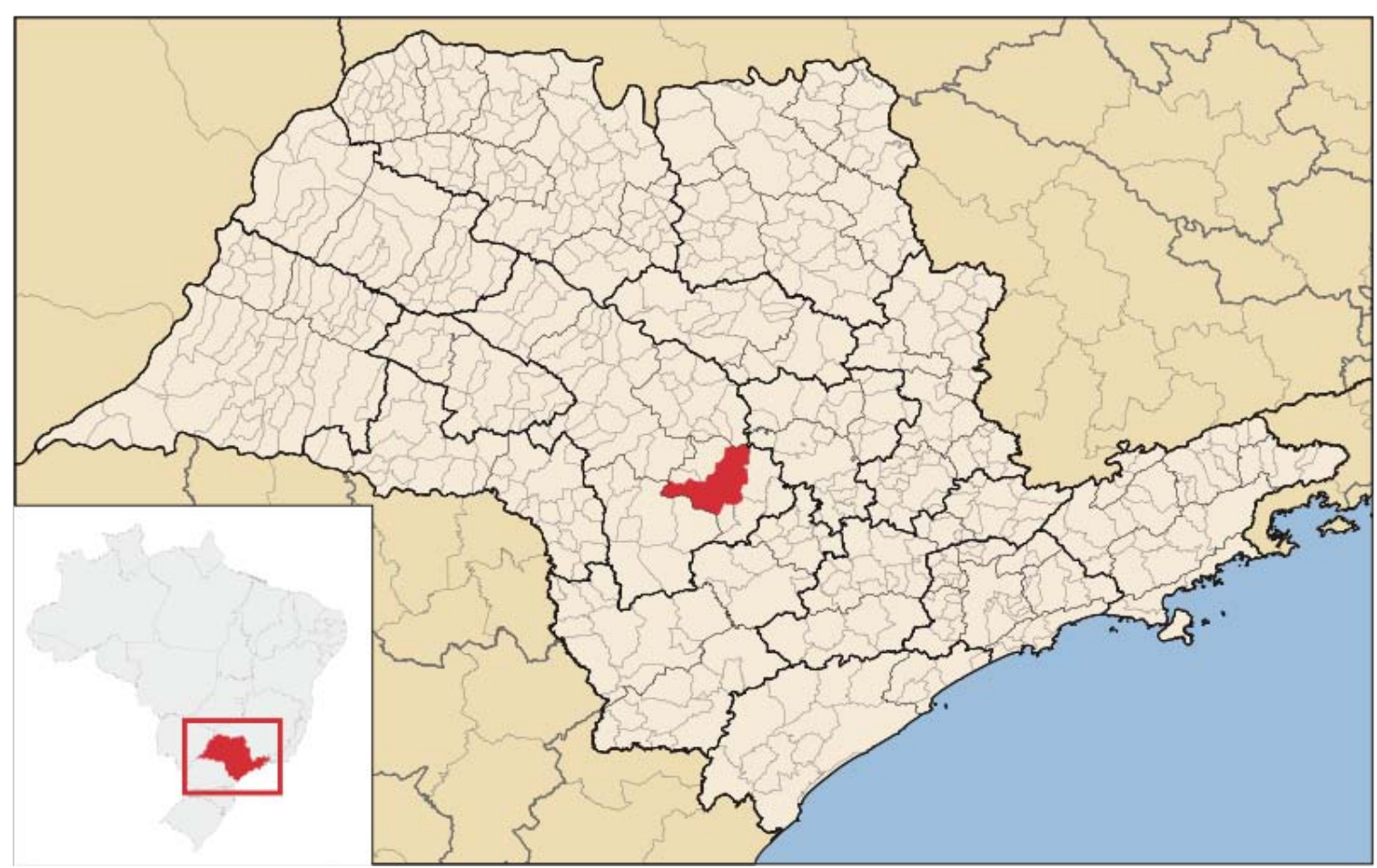

Figura 2: Localização de Botucatu no Estado de São Paulo. Fonte: http://pt.wikipedia. org/wiki/Ficheiro:Sao_Paulo_Municip_Botucatu.svg

Sua vegetação é marcada pela transição de Cerrado e de Mata Atlântica, fauna riquíssima e belas paisagens decorrentes das formações rochosas chamadas "Cuestas Basálticas".

O perímetro da cidade é cortado por uma APA (Área de Preservação Ambiental), criado com o intuito de preservar as áreas de recarga do aqüífero Guarani, entre outros, no conjunto APA Corumbataí, Botucatu, Tejupá, pelo Decreto Estadual n ${ }^{\circ} 20.960$ de 8 de junho de 1983, com uma área total de 649.8 ha.

"O Perímetro Botucatu possui uma área de 218.306 ha, contendo parte dos territórios de 9 municípios: Angatuba, Avaré, Bofete, Botucatu, Guareí, Itatinga, São Manuel, Pardinho e Torre de Pedra. Pertence à UGRHI 10 (Sorocaba Médio Tietê) e 14 (Alto Paranapanema). Este perímetro envolve a região da Serra de Botucatu, no reverso da Custa e ao sul, faz divisa com a represa de Jurumirim, marco na paisagem local e elemento indutor do turismo na região. Ainda são encontrados importantes remanescentes da vegetação nativa da Mata Atlântica e Cerrado, hoje refúgios da fauna local." (em: http://www.soscuesta.org.br/apa_botucatu.htm) 


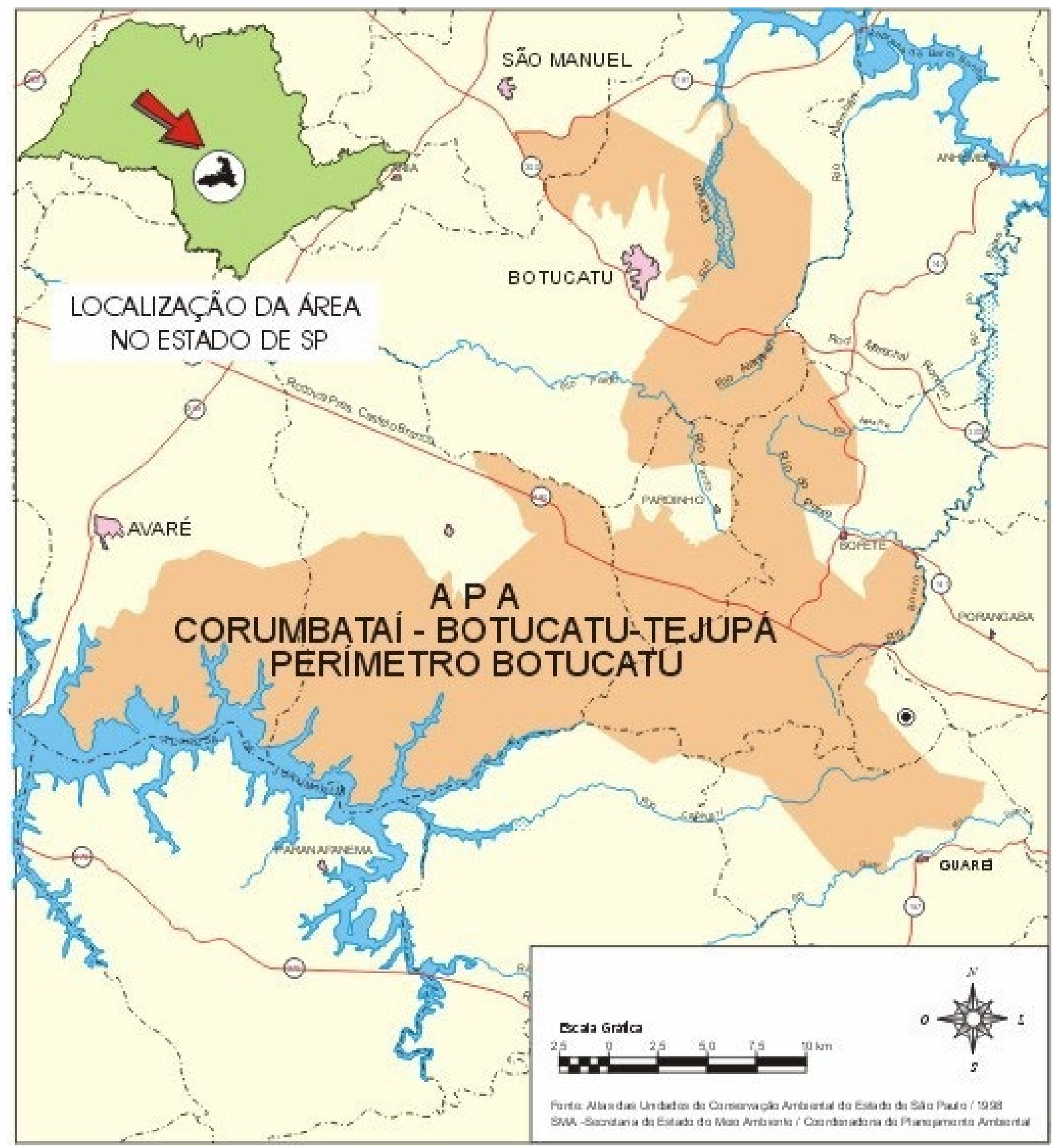

Figura 3: Localização da APA Botucatu e sua inserção na cidade. Fonte: Secretaria do Meio Ambiente. Coordenadoria de Planejamento Ambiental.

Os principais fatores de pressão à preservação da APA Perímetro Botucatu são: resíduos sólidos, mineração, esgotamento sanitário (urbano e industrial), agricultura (uso de agrotóxicos, erosão, assoreamento), expansão urbana e desmatamento. 


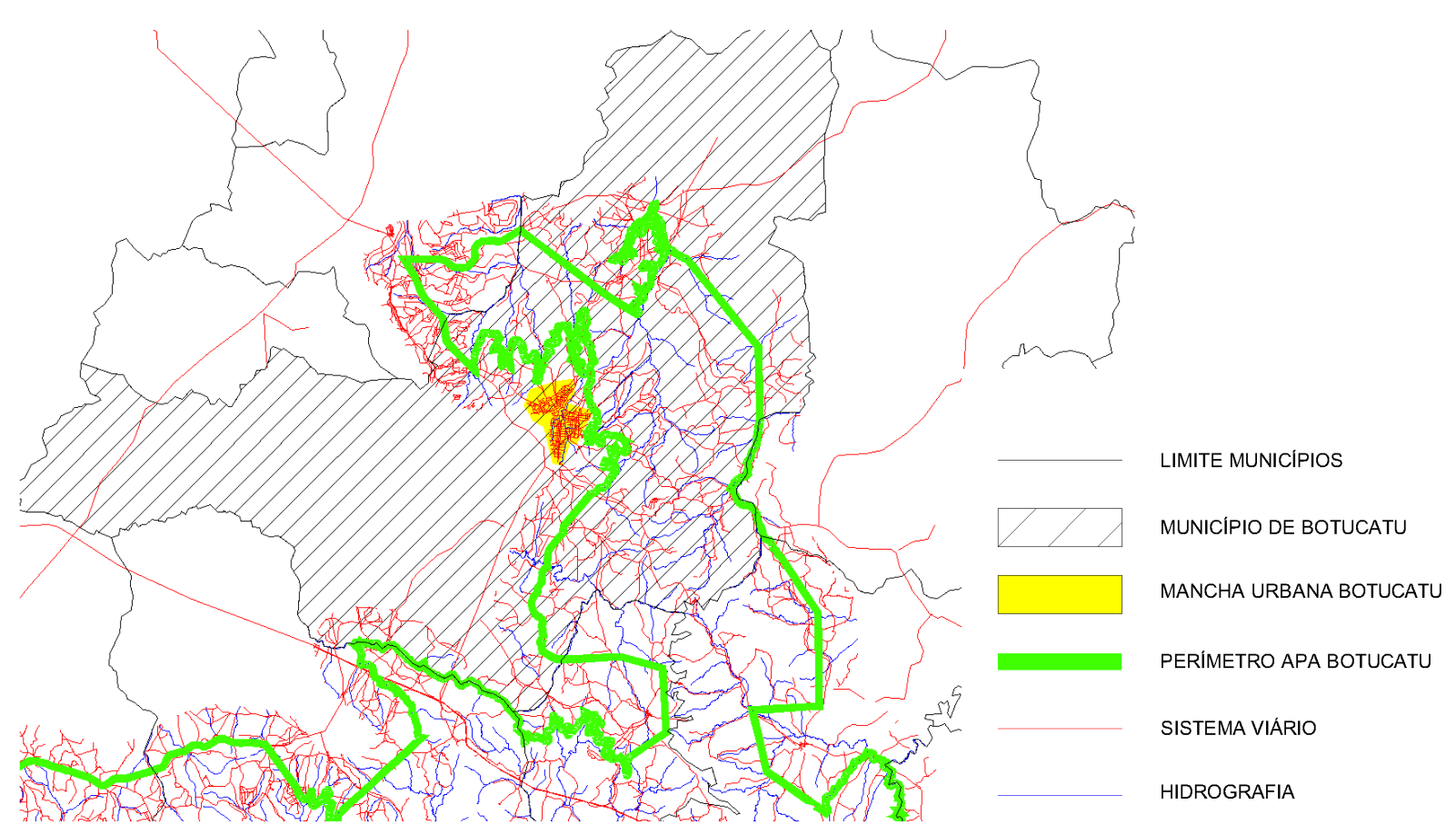

Figura 4: Mancha urbana x APA Botucatu. Fonte: Produção da autora.

Com o intuito de amenizar a pressão na APA Perímetro Botucatu, foi desenvolvido um Plano de Manejo, que é um documento técnico, elaborado para definir: o Zoneamento Ambiental, as normas e diretrizes do uso e ocupação dos solos, os programas de ação visando à proteção dos atributos ambientais e o desenvolvimento das atividades produtivas.

Assim, tendo em vista a importância ambiental de Botucatu, é imprescindível que seja analisado, seu principal instrumento de desenvolvimento urbano, o Plano Diretor Integrado de Botucatu, e que se verifique a existência ou não de diretrizes ambientais que visem à sustentabilidade e, além disso, a compatibilidade do mesmo com os demais Planos, como o Plano de Manejo da APA Botucatu.

\section{PLANO DIRETOR INTEGRADO DE BOTUCATU}

O Estatuto da Cidade é a denominação da lei 10.257 de 10 de julho de 2001, que regulamenta a Constituição Brasileira, em seu capítulo "Políticas Urbanas". Através de suas diretrizes, visa direcionar o desenvolvimento urbano de forma correta e equilibrada, assim, propôs a implementação de planos diretores aos municípios, com mais de 20 mil habitantes ou conurbados. Os Planos Diretores são portanto, os principais instrumentos de direcionamento do desenvolvimento urbano. 
O Plano Diretor Participativo de Desenvolvimento Integrado do Município de Botucatu é estabelecido pela Lei Complementar № 483, de 6 de junho de 2007.

O PDI Botucatu é dividido em seis partes:

Título I - Objetivos e princípios fundamentais

Título II - Da política de desenvolvimento regional

Título III - Da estrutura territorial municipal

Título IV - Das políticas de desenvolvimento social, econômico e ambiental

Título $\mathrm{V}$ - Da política de desenvolvimento urbano

Título VI - Do sistema de planejamento e gestão

Durante o Título I, o qual decorre sobre os principais objetivos do Plano, é notável a presença de diretrizes ambientais, que visam a preservação dos recursos naturais e o desenvolvimento sustentável, conforme Art. $3^{\circ}$. $\mathrm{VII}^{3}$.

No Título II, da Política de Desenvolvimento Regional, é destacada a importância da articulação de planejamento das municipalidades, a fim de solucionar questões em comum, como proteção e conservação dos recursos naturais e do Aqüífero Guarani, conforme Art. $9^{\circ} 4$.

3 Art. $3^{\circ}$. VII - potencialização dos recursos naturais, materiais, humanos e outros existentes no Município, públicos e privados, mediante o planejamento conjunto de sua utilização e desenvolvimento sustentável.

4 Art. 9 . São diretrizes básicas da política regional de desenvolvimento ambiental:

I - promover parcerias com os Municípios da região para a solução dos problemas comuns relativos à proteção, conservação e recuperação ambiental e ao uso sustentável dos recursos naturais; VII - promover a articulação regional para controle e diminuição de poluentes que ultrapassem as divisas regionais, através do ar e águas, incluindo resíduos industriais, esgotos, sólidos, provenientes de queimadas e outros. 
A Estrutura territorial municipal, Título III, define o Macrozoneamento da região conforme diretrizes da Lei Orgânica do Município e defina as seguintes macrozonas:

I - Macrozona Urbana de Adensamento Prioritário (MUAP)

II - Macrozona Urbana de Adensamento Secundário (MUAS)

III - Macrozona Urbana de Baixa Densidade (MUBD)

IV - Macrozona de Uso Rururbano (MUR)

$V$ - Macrozona de Atenção Ambiental (MAA)

VI - Macrozona de Uso Rural (MUR)

VII - Macrozona de Uso Rural Sustentável (MURS)

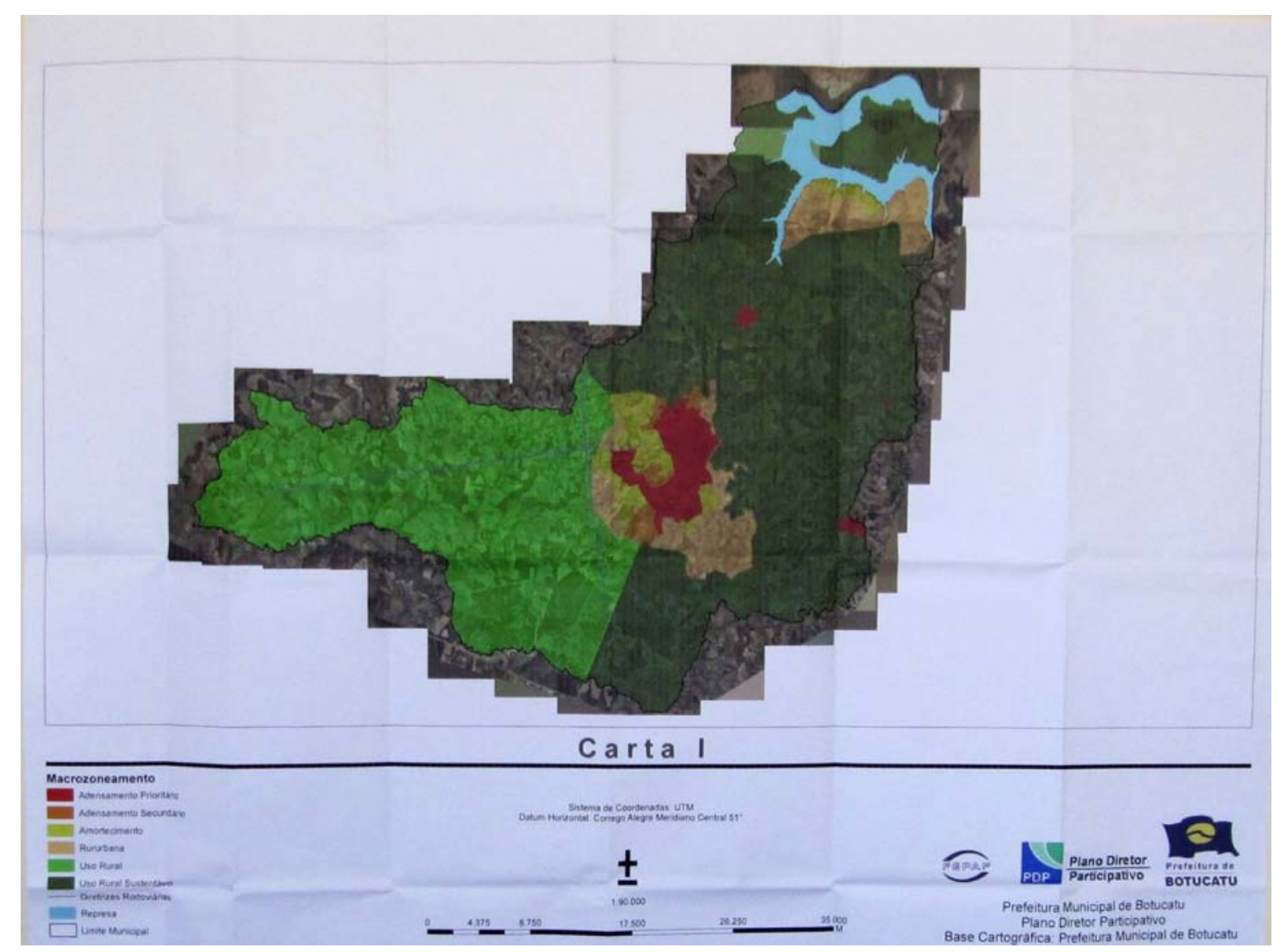

Figura 5: Carta I - Macrozoneamento. Fonte: Plano Diretor Integrado de Botucatu, em: www.botucatu.sp.gov.

A fim de identificar a compatibilidade ou não entre os planos de desenvolvimento existentes para a região de Botucatu, o cruzamento entre o Plano Diretor Integrado e o Plano de Manejo APA Botucatu é de extrema importância. A Figura 6 apresenta o mapa cruzando os respectivos planos e suas zonas.

Podemos identificar o primeiro cruzamento entre a zona ZCH2 com MUAP e MURS. 
A zona ZCH2, Zona de Conservação Hídrica 2 é destinada à proteção e a conservação da qualidade e quantidade das águas superficiais e subterrâneas com ênfase no Aqüífero Guarani, em áreas com alta fragilidade erosiva e declividade acentuada. Não é permitido na área: Loteamentos ou condomínios residenciais com lote ou fração ideal inferior a 5.000 m2 e impermeabilização superior a 20\% da área. Já na Macrozona Urbana de Adensamento Prioritário (MUAP): refere-se às áreas de urbanização consolidada, dotadas de infra-estrutura adequada à ocupação com alta densidade: fica estabelecido o lote mínimo de $250 \mathrm{~m}^{2}$ (duzentos e cinqüenta metros quadrados) para parcelamento ou desdobro visando à edificação;

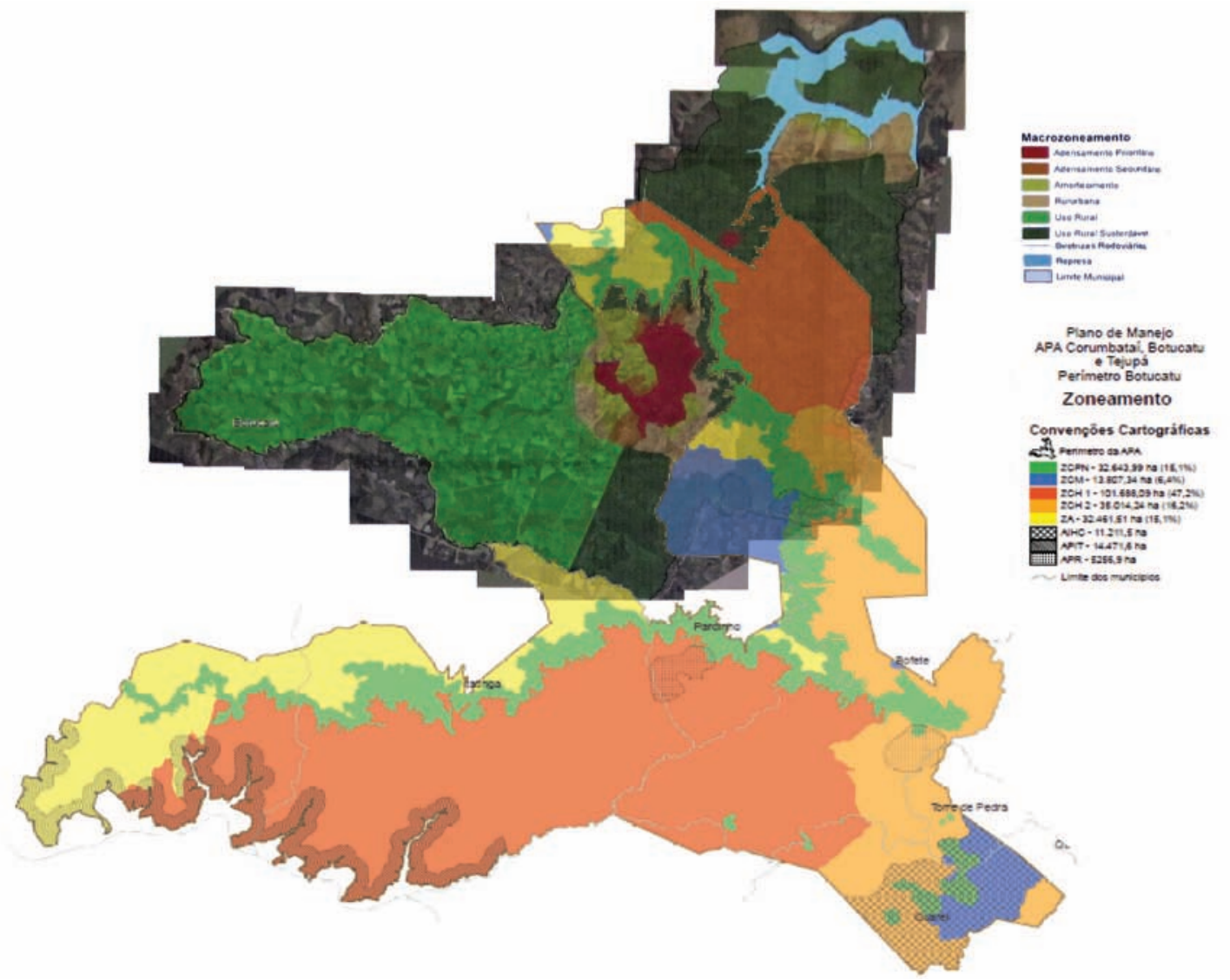

Figura 6: Cruzamento entre Plano Diretor Integrado de Botucatu e Plano de Manejo APA Botucatu. Fontes: Carta I - Macrozoneamento, Plano Diretor Integrado de Botucatu e Plano de Manejo APA Botucatu, produção da autora.

Fica evidente a discrepância entre os dois planos neste caso, porém com a Macrozona de Uso Rural Sustentável (MURS), onde deverão ser priorizadas as políticas de averbação e planejamento de reservas legais e Áreas de Preservação Permanente (APP), assim como as políticas de proteção e recuperação do solo, os planos se tornam compatíveis. 
O segundo cruzamento pode ser identificado entre a zona ZA com MUR e MURS.

A ZA, Zona Agrosilvopastoril é destinada ao incentivo da introdução e desenvolvimento de práticas, técnicas e atividades econômicas menos impactantes sobre os recursos naturais, com especial atenção aos recursos hídricos superficiais. Está situada na área do Aqüífero Guarani confinado, é incentivado o desenvolvimento de projetospiloto sustentáveis de produção rural que possam ser difundidos para outras zonas da APA e não são permitidos loteamentos e condomínios residenciais com área do lote ou fração ideal inferior a $2.000 \mathrm{~m} 2$ e impermeabilização superior a $20 \%$ da área. A zona ZA de forma geral está compatível com as diretrizes da Macrozona de Uso Rururbano (MUR), que se refere às áreas com restrições, pela fragilidade do meio natural ou pela ausência de infra-estrutura próxima, onde será permitido o parcelamento, através de empreendimentos a serem submetidos à apreciação do Grupo Interdisciplinar de Análise, com lotes mínimos de $4.000 \mathrm{~m} 2$ (quatro mil metros quadrados) e a Macrozona de Uso Rural Sustentável (MURS): semelhante à Macrozona de Uso Rural (MUR), já vista no item anterior.

Nos demais cruzamentos entre $\mathrm{ZCM}^{5}, \mathrm{ZCH}^{6}, \mathrm{ZCPN}^{7}$ com MUR e MURS, pode-se observar compatibilidade semelhante ao item anterior, porém o Plano de Manejo da APA mostra-se sempre mais detalhado e restritivo. Como por exemplo:

A Zona de Conservação dos Mananciais é destinada a conservar e garantir a qualidade e quantidade das águas dos mananciais de abastecimento público e restringir as atividades ou obras que potencializem o risco de erosão do solo e a contaminação dos recursos hídricos. Para as áreas de Conservação de Mananciais, localizadas fora do perímetro da APA, mas contíguas à ZCM, recomenda-se a adoção das mesmas diretrizes e normas de uso adotadas para a Zona.

5 ZCM - Zona de Conservação dos Mananciais.

6 ZCH1 - Zona de Conservação Hídrica 1.

7 ZCPN - Zona de Conservação do Patrimônio Natural. 
Não são permitidos nessa área: Aeroportos e dutovias caso existam alternativas locacionais; obras hidráulicas, sistemas de drenagem e de irrigação de grande porte a exemplo de pivô central e canhão hidráulico; aterros sanitários, de construção civil, necrópoles e curtumes; distritos industriais; usinas de geração de energia elétrica, usina de açúcar, álcool e cogeração de energia; loteamentos residenciais com área do lote inferior a $5.000 \mathrm{~m} 2$, com taxa de impermeabilização superior a 20\%; pulverização de plantações com agrotóxicos através de aeronaves.

Isso pode servir como direcionamento do Macrozoneamento, ou seja, o Plano de Manejo da APA, nos locais de interseção com o Plano Diretor Integrado de Botucatu, deveria prevalecer sobre o Plano Diretor Integrado de Botucatu e constar nas diretrizes da Lei.

Dando continuidade à análise do Plano Diretor Integrado de Botucatu, ainda no Título III, Capítulo II ${ }^{8}$, podemos perceber o incentivo à criação e proteção de zonas especiais como, por exemplo, as Zonas Especiais de Proteção Ambiental (ZEPAM).

"Art. 23. Para a delimitação e criação de ZEPAM, devem ser observados, entre outros, os seguintes critérios:

(...)

III - criação de corredores de biodiversidade, a serem planejados conjuntamente pelo Poder Público, pela iniciativa privada e pela sociedade civil, integrando maciços florestais principais;

IV - delimitação e averbação das Áreas de Preservação Permanente (APP) e reservas legais; $\mathrm{V}$ - proteção de áreas de cerrado;

VI - proteção e monitoramento de áreas de recarga do Aqüífero Guarani, principalmente com respeito à incidência de agrotóxicos." (Plano Diretor Integrado de Botucatu, em: www.botucatu.sp.gov.br)

Ainda no mesmo Título II, na Seção I ${ }^{9}$, Art.28. IV, há o incentivo a promover o adensamento ao longo dos corredores de transportes. Tanto a criação de Zonas Especiais quanto a otimização dos corredores dos transportes são diretrizes que visam um de-

8 Capítulo II - Das Zonas Especiais.

9 Uso e Ocupação do Solo 
senvolvimento sustentável, porém, a carência de cartografia com qualidade e diretrizes mais detalhadas e específicas impedem uma análise mais profunda.

O Título III decorre sobre a estrutura territorial municipal. Neste também, se encontram diretrizes que podem ser consideradas sustentáveis, como o Art. 73 II, "priorizar as indústrias destinadas à tecnologia de saneamento ambiental e à tecnologia de habitação e transporte ecológicos" e o Art. 89, "adotar as microbacias hidrográficas como unidades de planejamento,..., com vistas ao desenvolvimento rural sustentável".

Ambos os temas, a instalação de indústrias e o desenvolvimento rural são de extrema importância para o desenvolvimento sustentável na região, levando em consideração a pressão que ambos representam na proteção da APA Botucatu, como visto anteriormente.

"Art. 92. O Poder Público Municipal deverá apoiar a revisão dos limites da APA Botucatu, objetivando sua ampliação."

(Plano Diretor Integrado de Botucatu, em: www.botucatu.sp.gov.br)

Tendo em vista a importância do assunto mobilidade nas premissas de desenvolvimento sustentável, o PDI Botucatu se apresenta contraditório.Embora apresente diretrizes positivas como, priorizar o transporte coletivo em relação ao individual (Título V - Art. 118), e a solicitação de um Plano de Trânsito, Transporte e Mobilidade Municipal que contemple um programa de ciclovias e a interligação do transporte intermunicipal com o transporte urbano (Título V - Art. 119). Por outro lado, prevê a construção de avenidas marginais ao longo do Ribeirão Lavapés, que deveria ser considerado como corredor ecológico ou de biodiversidade, como a mesma Lei prevê em artigos anteriores Art. 94 (Título IV) ${ }^{10}$ e Art. 120 (Título V) ${ }^{11}$.

10 "Art. 94. São diretrizes da política municipal do meio ambiente:

I - preservar, melhorar e recuperar o meio ambiente;

II - conservar, preservar e recuperar as áreas verdes, os fundos de vale, das minas e nascentes, córregos, riachos e rios;

III - criar, proteger e recuperar as áreas de relevância ambiental e de ecossistemas originais."

11 "Art. 120. As Áreas de Fundo de Vale e Áreas de Preservação Permanente dos cursos d'água que cortam as áreas urbanas do Município deverão ser objeto de plano específico, com as seguintes diretrizes: I - garantir a preservação das qualidades paisagísticas e ambientais." 
"Art. 125. Prever a construção de avenidas marginais ao longo do Ribeirão Lavapés, mediante prévio estudo da viabilidade urbanística e ambiental.

Parágrafo único. Impedir a construção de novos imóveis dentro da faixa das margens do Ribeirão Lavapés que possam inviabilizar ou prejudicar a construção da avenida marginal citada no caput deste artigo."

(Plano Diretor Integrado de Botucatu, em: www.botucatu.sp.gov.br)

Segundo PIZA, o sistema viário da cidade não conta com grandes avenidas e sempre esteve esperando por uma solução, como as avenidas marginais de fundo de vale, que foram previstas em todos os Planos Diretores, 1967,1973, 1987 e 1998, e agora novamente em 2007.

Esta postura vem sendo modificada, e novos estudos vêm sendo incorporados a fim de melhorar a mobilidade urbana, sem a criação das avenidas marginais de fundo de vale.

Porém, ainda segundo PIZA, um dos estudos, realizado em conjunto com a FATECBotucatu, previa a construção de um sistema de transporte coletivo de grande capacidade ao invés das marginas, no mesmo trajeto.

O investimento em transporte coletivo de alta capacidade ao invés de avenidas marginais é realmente significativo, porém a localização dessas linhas em fundo de vale ainda não se justifica. A promoção do uso da bicicleta bem como implantação de ciclovias e outros meios de conexão com a rede de transportes podem ser adotadas como medidas de sustentabilidade, e o fundo de vale ser considerado como um corredor ecológico, conectado nos demais parques da cidade e com diretrizes previstas pela Secretaria de Meio Ambiente, ou seja, deve ser considerado objeto de desenvolvimento e preservação ambiental e não urbano e viário.

"Quanto à recusa em construir as avenidas marginas, foi necessário construir uma alternativa política de transportes que promovesse a mobilidade urbana baseada em metas de recuperação do transporte público e na promoção do uso da bicicleta." (PIZA,) 


\section{CONCLUSÃO}

Tendo em vista que está prevista uma revisão do Plano Diretor Integrado de Botucatu para o próximo ano, esta pesquisa visa apenas apontar alguns aspectos que possam vir a colaborar para que o Plano Diretor e a cidade aprimorem suas diretrizes visando um desenvolvimento sustentável.

Ao analisar o Plano Diretro Integrado de Botucatu, com ênfase em detectar premissas sustentáveis, de uma maneira geral, o mesmo se apresenta a favor do desenvolvimento sustentável, porém com alguns aspectos contraditórios, dispersos ou insuficientes para a continuidade do processo.

Primeiro aspecto a ser destacado é a ausência de mapas com qualidade tanto para a análise desta pesquisa, quanto para consulta e desenvolvimento da região de acordo com as premissas estipuladas, e definições mais detalhadas e precisas dos perímetros das áreas de Zonas Especiais e de Preservação Ambiental, para que as mesmas possam ser respeitadas e desenvolvidas de acordo com o Plano.

A falta de relação do Plano Diretor com o Plano de Manejo da APA Botucatu, onde em uma das áreas de interseção dos Planos, apresentam regras opostas, como adensamento prioritário $X$ zona de conservação hídrica.

E por último a projeção de uma via marginal no Ribeirão Lavapés, que contradiz muito com as diretrizes de preservação e promoção de corredores ecológicos para áreas de fundo de vale, visto as experiências de São Paulo, que agora tenta consertar com os programas de Parques Lineares e Córrego Limpo.

"O novo Plano Diretor prevê a elaboração de planos urbanísticos detalhados, que deverão priorizar a preservação das áreas verdes, e a produção de espaços de convívio, substituindo a prioridade dos projetos antigos, que era a de promover o fluxo de veículos." (PIZA)

A adoção de medidas sustentáveis esbarra em diferentes obstáculos desde sua teoria até sua aplicação, porém cabe aos urbanistas, pesquisadores e tomadores de decisões incorporá-las no planejamento urbano e torná-las como "desenvolvimento padrão", assim, a sociedade como um todo poderá tornar-se realmente sustentável. 
"Deve ser de longo prazo, com planos e projetos atrativos. Sua implantação pode ser difícil, por isso os designers devem alertar os tomadores de decisões das conseqüências de um desenvolvimento não-sustentável e ressaltar a importância da sustentabilidade, e sua incorporação na legislação de desenvolvimento tradicional." (Sustainable Urban Design - The next step: Examples and perspectives)

\section{BIBLIOGRAFIA}

BRANCO, Samuel Murgel. Ecologia da cidade. Editora Moderna, 1991.

COMISSÃO MUNDIAL SOBRE MEIO AMBIENTE E DESENVOLVIMENTO. Nosso futuro comum. $2^{\text {a }}$ ed. Rio de Janeiro: FGV, 1991.

CONFERÊNCIA DAS NAÇÕES UNIDAS SOBRE MEIO AMBIENTE E DESENVOLVIMENTO, 2, 1992, Rio de Janeiro. Agenda 21. Brasília: Senado Federal, Subsecretaria de Edições Técnicas, 1996.

FÁVERO, Oriana Aparecida. Paisagem e sustentabilidade na Bacia hidrográfica do rio Sorocaba. São Paulo, 2007. Tese de Pós-graduação em Geografia Humana, da Faculdade de Filosofia, Letras e Ciências Humanas da Universidade de São Paulo.

FRANCO, Maria de Assunção Ribeiro. Planejamento ambiental para a cidade sustentável. São Paulo: Annablume: FAPESP, 2000.

PIZA, J.F.B.T. O tratamento dado às APPs e APA no Plano Diretor Participativo de Botucatu, em: <arquitetura.ufc.br>.

FUNDAÇÃO FLORESTAL DO ESTADO DE SÃO PAULO, Plano de Manejo da APA Corumbataí, Botucatu e Tejupá - Perímetro Botucatu - Volume II. São Paulo 2011. PREFEITURA DE BOTUCATU, Plano Diretor Participativo de Desenvolvimento Integrado do Município de Botucatu - Lei Complementar № 483, de 6 de junho de 2007. em: <www.botucatu.sp.gov.br>.

ROGERS, Richard. Cidades para um pequeno planeta. Barcelona: Gustavo Gili, 1997. 
RUANO, Miguel. Ecourbanismo: entornos urbanos sostenibles: 60 projectos. Barcelona: Gustavo Gili, 1999.

SOS CUESTA, APA Corumbataí, Botucatu e Tejupá, em: <www.soscuesta.org.br>.

WORKING GROUP ON SUSTAINABLE URBAN DEVELOPMENT OF THE DUTCH PROFESSIONAL ORGANISATION OF URBAN DESIGNERS AND PLANNERS. SUStainable Urban Design - The next step: Examples and perspectives. Holanda: 2011. 